\title{
Large Animal Models for Vascularized Composite Allotransplantation
}

\author{
Jhade D. Woodall • Benjamin D. Schultz • Michael Sosin • \\ Rolf N. Barth
}

Published online: 19 June 2014

(C) Springer International Publishing AG 2014

\begin{abstract}
Large animal models have served as the foundation for clinical trials in all solid organ transplantation. Likewise, pre-clinical studies in vascularized composite allotransplantation (VCA) have provided a foundation for initial human applications in VCA. The growth of clinical VCA correspondingly benefits from large animal studies investigating the unique immunobiology, improved immunosuppressive regimens, and the potential induction of immunologic tolerance. VCA studies in large animal models of nonhuman primates, swine, and canines have and continue to build knowledge towards improved clinical outcomes.
\end{abstract}

Keywords Vascularized composite allograft $\cdot$ Composite tissue allotransplantation · Large animals · Canines · Swine . Nonhuman primate $\cdot$ Chimerism $\cdot$ Tolerance $\cdot$ Transplantation

\section{INTRODUCTION}

Vascularized composite allotransplantation (VCA) offers possibilities in the management of disfiguring complex tissue loss. Encouraging outcomes in VCA have been recognized in hand and upper extremity, face, abdominal wall [1], larynx [2], and lower extremity [3] transplantation. The progression of VCA into the clinical realm has been supported by preclinical, large animal studies investigating the immunobiology of these unique tissues. Similar to solid organ transplants that are often life-saving, VCA success depends on life-long immunosuppression with its associated risks and complications. Research goals continue to be directed towards the development of a VCA protocol that supports prolonged graft survival

J. D. Woodall • B. D. Schultz $\cdot$ M. Sosin • R. N. Barth $(\bowtie)$ University of Maryland School of Medicine, 29 South Greene Street, Suite 200, Baltimore, MD 21201, USA

e-mail: rbarth@smail.umaryland.edu and minimizes or eliminates immunosuppression. Additional knowledge regarding the mechanisms of rejection and functional outcomes of VCA are also well modeled in large animals. These studies in non-human primates (NHP), swine, and canines have been predictive of success and challenges in clinical VCA protocols (Table 1).

\section{NONHUMAN PRIMATES}

Nonhuman primate (NHP) models of VCA have been developed and refined over the last few decades to study monitoring and treatment strategies for VCA. Early work in NHPs focused on the technical and immunosuppression requirements to develop a model with reliable outcomes, low morbidity, and prolonged survival. The involvement of the motor-sensory portion of VCA responsible for functional re-innervation allowing grasping, mastication, and blinking [4-8], was investigated in the first NHP studies.

In 1984, Egersezi reported on two VCA models in baboons using cyclosporine (CsA) to study the immunological and functional recovery aspects of hand transplantation. The first microsurgical transfer was a neurovascular free flap (NVFF) and consisted of the soft tissue coverage of the second digit with anastomosis of the associated neurovascular structures. Immunosuppression consisted of CsA titrated to levels of $800 \mathrm{ng} / \mathrm{mL}$ starting 4 days before transplantation. Rejection episodes were treated by increasing CsA to a level of $1,000 \mathrm{ng} / \mathrm{mL}$ with a steroid bolus and tapered to a maintenance dose of $5 \mathrm{mg} /$ day. Survival up to 161 days was reported, although survival was inconsistent [4].

Daniel et al demonstrated better technical outcomes of NVFF transplantation with the addition of steroid therapy. Despite three animals experiencing rejection, four animals survived rejection free to postoperative day (POD) 132. These authors further performed four complete hand transplants 
Table 1 Summary of papers with significant contributions to the field of VCA in large animal models

\begin{tabular}{|c|c|c|c|c|}
\hline Model & Author/Date & Conditioning & IS & Conclusion \\
\hline \multirow[t]{3}{*}{ Swine } & Fuchimoto, 2000 & TI, TCD,PBSC infusion & CsA for 30 days & $\begin{array}{l}\text { Stable chimerism is associated with graft } \\
\text { tolerance across major MHC barriers. }\end{array}$ \\
\hline & Cetrulo, 2013 & Kidney Tx & CsA 12 days & $\begin{array}{l}\text { Skin tolerance requires more than MHC I } \\
\text { tolerance. }\end{array}$ \\
\hline & Leonard, 2014 & TBI, TCD, PBSC & CsA for 45 days & $\begin{array}{l}\text { Tolerance to skin is induced with this } \\
\text { regimen in haploidentical animals. }\end{array}$ \\
\hline \multirow[t]{2}{*}{ Nonhuman Primate } & Daniel, 1986 & none & CsA & $\begin{array}{l}\text { Hand transplant model is technically } \\
\text { feasible. }\end{array}$ \\
\hline & Barth, 2011 & none & $\mathrm{FK} / \mathrm{MMF}$ & $\begin{array}{l}\text { Inclusion of VBM prolongs graft survival } \\
\text { but does not induce tolerance despite } \\
\text { chimerism. }\end{array}$ \\
\hline Canines & Mathes, 2011 & $\begin{array}{l}\text { Nonmyeloablative allogenic } \\
\text { hematopoietic stem cell tx }\end{array}$ & CsA & $\begin{array}{l}\text { Establishment of mixed hematopoietic } \\
\text { chimeras induces donor specific- } \\
\text { tolerance to all components of a } \\
\text { myocutaneous flap. }\end{array}$ \\
\hline
\end{tabular}

$I S$, Immunosuppressive regimen, $T x$, transplantation, $T I$, Thymic Irradiation, $T B I$, Total Body Irradiation, $T C D$, Tcell depletion, $P B S C$, Peripheral blood stem cells, CsA, cyclosporine A, FK, FK 506, MMF Mycophenolate Mofetil

demonstrating long-term survival to POD 304 and restored function. Results were likewise variable with one hyperacute rejection episode and two acute rejection episodes 60 days postoperatively [5].

Stark et al reported that from eight NHP hand transplants, six failed by POD 15, including two technical losses. CsA and steroid therapy resulted in only one allograft survival to POD 296. Despite acute rejection episodes, animals displayed evidence of successful motor and sensory re-innervation. Histology of the early losses showed acute necrotizing rejection and signs of rejection present in all soft tissue; however, rejection was most prominent at the dermoepidermal junction. While donor bone marrow was depleted of viable cells, "patchy lymphoplasmacellular infiltrates" were present in the recipient tissues. These findings raised concerns for both graft-versushost disease (GVHD) and post-transplant lymphoproliferative disorder (PTLD) as well as unique concerns regarding donor bone marrow and robust skin rejection [6].

In the early 1990s, Stevens reported on a Rhesus monkey model of osteomyocutaneous first ray of the hand (thumb) with a radial forearm flap VCA. Immunosuppression consisted of CsA maintenance therapy with a target above $400 \mathrm{ng} / \mathrm{mL}$ with steroid induction and maintenance. Half of the animals received preoperative, third party blood transfusions. In some of the animals, rejection was treated with a cocktail of monoclonal antibodies (mABS) while others were treated with steroids. Results were reported for 12 transplants with 10 of the animals undergoing rejection. Monoclonal antibodies were able to reverse some rejection whereas steroids were not. Blood transfusions had no effect on rejection. Three animals had graft survival over 100 days with the others being lost between day 21 and 85 . In all long-term survivors, there was evidence of re-innervation [7]. Mortalities were secondary to anaphylaxis following $\mathrm{mAB}$ administration, opportunistic bacterial infections, and lymphoid tumors. Importantly, viral mismatching was implicated in the development of lymphoid tumors, which remains clinically relevant. While rejection was regularly observed, less toxic immunosuppression was an important focus for future studies [9].

Pharmacological advancements including more potent calcineurin inhibitors, such as tacrolimus, allowed for new immunosuppressive regimens in VCA models. Cendales et al developed a radial osteomyocutaneous flap in cynomolgus macaques utilizing tacrolimus $(15-20 \mathrm{ng} / \mathrm{mL})$, mycophenolate mofetil (MMF), and maintenance steroids. Control animals without immunosuppression rejected by day 8 , whereas allograft survival in immunosuppressed NHP was achieved up to POD 76. Observations of acute rejection patterns were histologically analogous to those observed in human VCA rejection with $\mathrm{CD} 3+\mathrm{T}$ cell lymphoid infiltrates in the dermis and perivascular distribution along with a weaker infiltrate of CD4+ T cells near dermal capillaries. Six of the seven immunosuppressed recipients also developed anti-donor antibodies providing new concern for a humoral component of acute rejection [10].

An NHP model for heterotopic face transplantation has also been established [11]. Technical and immunosuppressive modifications provided reliable and replicable outcomes providing a platform for prolonged VCA survival in a NHP model (Fig. 1). Tacrolimus monotherapy with increased levels prevented rejection, but a unique complication of a high incidence of PTLD was recognized [12]. PTLD was unique in this VCA model in that it was predominantly donor-derived (unlike solid organ PTLD, which is recipient-derived), and it was 
associated with lymphocryptovirus (LCV). Alternate immunosuppressive therapies such as the m-TOR inhibitor rapamycin resulted in allograft rejection soon after conversion [13].

This model also assessed the role of vascularized bone marrow (VBM) comparing facial VCA transplants with and without VBM. The immunosuppression regimen had been slightly modified to include MMF and lower levels of tacrolimus. Animals without VBM components to the VCA grafts promptly rejected their allografts compared to VCA with VBM where graft survival continued without rejection for over 1 year as long as immunosuppression was continued. Three of four VBM monkeys demonstrated at least transient macrochimerism in peripheral blood; however, after withdrawal of immunosuppression all VCA rejected within 60 days. Nonetheless, the donor VBM compartment was found to contain viable donor bone marrow [14•]. While VBM was associated with prolonged VCA survival, recipient chimerism was not associated with the development of tolerance. Furthermore, characteristics of chronic rejection including vasculopathy, neointimal proliferation, and vessel occlusion were observed in those animals with long-term (greater than 200 days) survival, but without CD4+ deposition and only minimal evidence of alloantibody production [15], findings which are consistent with reports in human hand transplantation [18]. Further investigation of outcomes with regulatory $\mathrm{T}$ cells (Treg) did not reveal convincing associations [17]. This may be due to the severity of rejection overwhelming the regulatory process of the cellular immune response. This immunosuppressive approach was applied to a fibula VCA; however, all grafts were lost from technical and immunologic causes with no evidence of viable donor marrow [16]. These alternate findings suggested the immunologic benefit may be related to donor bone marrow volume.

Improved technical and immunosuppressive strategies have permitted NHP models to become feasible, replicable, and reliable in studying a variety of immunosuppressive regimens, the impact of VBM, and the immunobiology of these allografts. Ongoing studies focus on approaches that reduce or eliminate immunosuppressive requirements and further understand the unique component of VBM.

\section{SWINE}

Large animal models in swine have been developed for VCA transplantation of orthotopic and heterotopic transplantation of the forearm, leg, face, abdominal wall, and gracilis myocutaneous flap. While functional outcomes of VCA have been more challenging, swine large animal VCA studies have proven to yield excellent technical results with low animal morbidity [19-23]. Studies have been focused on the development of donor-specific tolerance similar to multiple successful swine models of tolerance for solid organ transplantation.

An initial model of orthotopic radial forelimb allograft from outbred farm swine with immunosuppression consisting of CsA, MMF, and prednisone [24] demonstrated that VCA could survive long-term (greater than 90 days) without skin rejection or GVHD. While acute rejection $(n=2)$, mild to moderate rejection (Grade I-II) $(n=5)$, as well as infections including pneumonia and septic arthritis were observed, the protocol was clinically relevant [24]. When immunosuppression was modified to tacrolimus (trough level $3-8 \mathrm{ng} / \mathrm{mL}$ ), MMF, and steroids, an improved rejection profile was observed [25]. These models provided evidence that swine VCA could be a reliable model for further investigations that later included defined SLA (swine leukocyte antigen) mismatching and functional VCA subunits using inbred swine [26].

Massachusetts General Hospital (MGH) miniature swine provided defined genetic barriers to investigate more specifically the immunologic barriers to VCA. The use of selective SLA matching and mismatching for VCA experiments in this inbred colony allowed for more sophisticated immunologic studies that investigated tolerogenic protocols. A model of heterotopic hind limb transplant in SLA matched miniature swine described a phenomenon of split tolerance [27, 28]. A VCA consisting of tibia, fibula, knee joint, femur, and muscle (without skin) (Fig. 2) with 12-day CsA immunosuppression survived between 178 and 280 days without evidence of rejection. Mismatched animals not receiving CsA survived only 42 days and SLA-matched swine without CsA survived 84 days. This model supported SLA matching and heterotopic transplants that allowed animals to ambulate with minimal morbidity [27]. SLA-matched, minor antigen-mismatched swine receiving musculoskeletal allografts without skin treated with a 12-day course of CsA accepted both the VCA and subsequent donor-type skin grafts [28]. SLA-mismatched recipients treated with the same short-course of CsA rejected their musculoskeletal allografts [29]. These experiments supported evidence of a skin-specific immune response revealing that $\mathrm{MHC}$ tolerance is not the only requirement for acceptance of skin [28].

Numerous swine models have defined the establishment of chimerism as one method to induce donor-specific tolerance to solid organ allografts. SLA-matched swine with minor antigen mismatch and a short course CsA showed no evidence of rejection at the time of euthanasia (between POD 178 and 372), although donor skin grafts were not universally accepted. Transient chimerism was observed up to POD 19 in peripheral blood [30]; however, donor bone marrow space was replaced with recipient $T$ cells by 10 weeks [31]. The addition of a skin paddle (Fig. 3) revealed skin rejection by POD 60 without affecting other components of the graft [32]. The rejection of skin supported an alternate mechanism for 

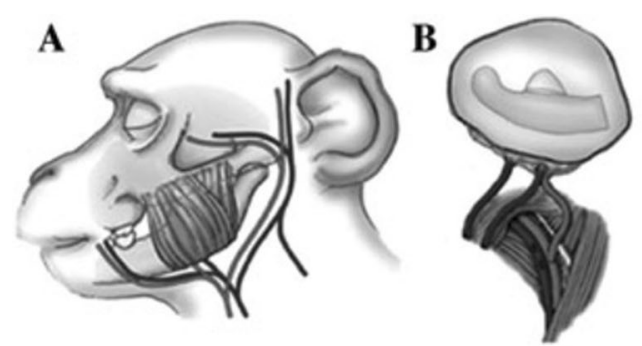

Fig 1 Model of nonhuman primate VCA of partial facial allografts. (a) Segments of face procured from donors included mandible, masseter, overlying skin, arterial inflow via common carotid artery and drainage via internal and external jugular veins. (b) Allografts heterotopically transplanted with vascular anastomoses to recipient femoral vessels. (c) Allografts inlaid into the lower abdominal wall and sutured to

skin rejection such as antigen-presenting cells, including Langerhans cells or dermal dendritic cells, which have a dominant presence in the skin. Further studies investigated swine tolerant to SLA Class I mismatched kidneys transplanted with donor-matched myocutaneous flaps revealed rejection of the skin by day $40\left[33^{\bullet}\right]$.

Non-myelosuppressive regimens that permit stable chimerism and tolerance to VCA transplantation were investigated in a mismatched miniature swine limb VCA model. Treatment

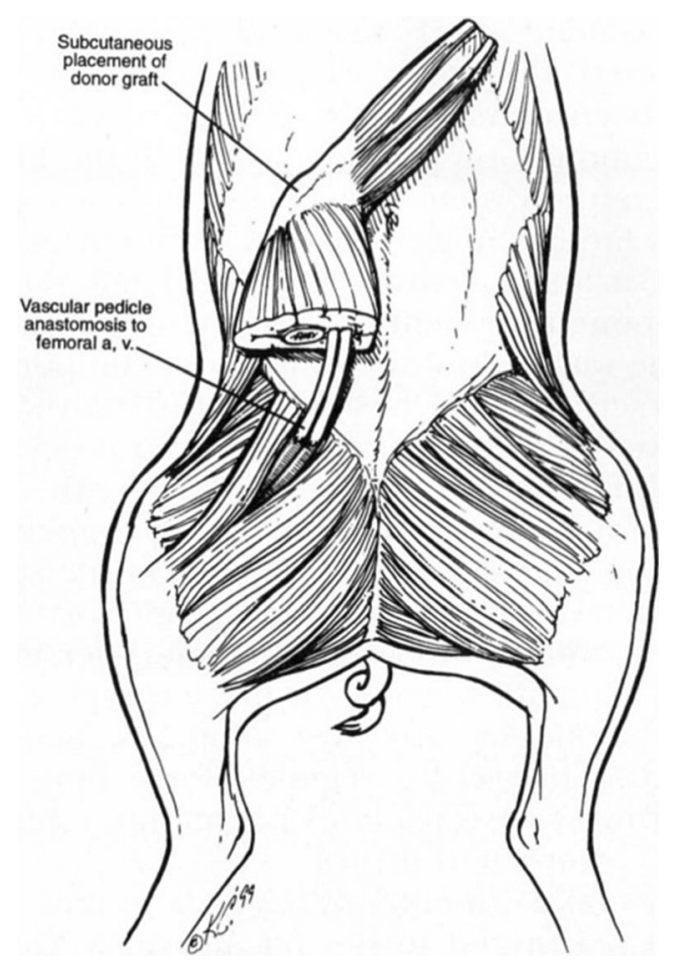

Fig 2 Musculoskeletal allograft inset in a subcutaneous pocket of the abdominal wall with perfusion occurring through femoral-to-femoral anastomosis. (With permission from: Lee WP, Rubin JP, Bourget JL, Cober SR, Randolph MA, Nielsen GP, et al. Tolerance to limb tissue allografts between swine matched for major histocompatibility complex antigens. Plast Reconstr Surg. 2001;107:1482-1490) [29].
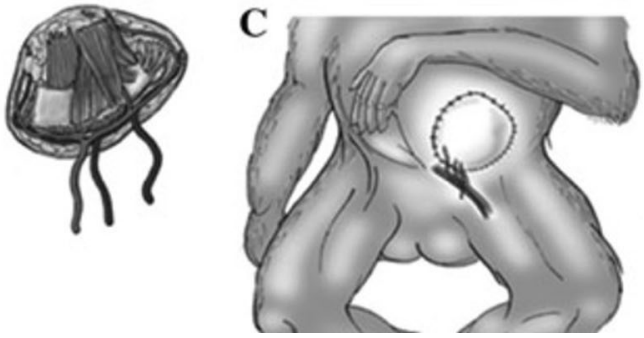

surrounding skin. (With permission from: Barth RN, Rodriguez ED, Mundinger GS, Nam AJ, Ha JS, Hui-Chou H, et al. Vascularized bone marrow-based immunosuppression inhibits rejection of vascularized composite allografts in nonhuman primates. Am J Transplant. 2011;11(7):1407-16) [14•].

with $\mathrm{T}$ cell depletion, CsA, and either bone marrow cells (BMC) or mobilized PBSCs in mismatched animals showed long-term acceptance of the musculoskeletal elements of the graft, but rejected the cutaneous portions by day 50. PBMCs provided macrochimerism; however, GVHD was also observed. BMC recipients developed neither chimerism nor GVHD [34]. Modifications of high-dose infused BM, VBM with tacrolimus, and CTLA 4 IG (a costimulatory blockage antagonist) permitted skin survival to 150 day endpoints without histologic evidence of rejection and transient microchimerism [33•]. This improved immunosuppressive approach provided for transient microchimerism and skin survival.

This model also investigated VCA and mesenchymal stem cell (MSC) transplantation [34]. MSC therapy prolonged VCA graft survival and increased Treg populations compared to no treatment, but this had been part of therapy with irradiation, BMC, MSCs, and CSA for 4 weeks [35]. The effect of MSC was preserved without BMCs [36]. This model was expanded to an orthotopic facial VCA using MSCs and CsA [37]. MSCs combined with other treatments supported long-term acceptance to all components of a VCA including the skin.

More recent studies showed long-term tolerance towards all components of a swine limb VCA. Irradiated, T cell-depleted animals received donor mobilized PBMCs with CsA in the setting of one MHC haplotype mismatch. Two animals underwent simultaneous VCA of a fasciomyocutaneous flap resulting in long-term acceptance of all components. Three other animals underwent delayed VCA transplantation at day $85-150$ in recipients shown to have stable mixed chimerism via in vitro assays depicting donor specific tolerance. These animals also accepted all tissue components of the allograft. Animals showed evidence of stable, long-term, multi-lineage chimerism in the range of $20-100 \%$; however, two animals showed evidence of GVHD. One proposed mechanism for this skin tolerance, which is based on the reported finding of high amount of $\mathrm{CD} 3+/ \mathrm{FOXP} 3+$ cells in the skin but not peripherally 
Fig 3 Heterotopic transplantation of vascularized composite allograft consisting of bone, musculoskeletal tissue, and skin. (With permission from: Mathes DW, Randolph MA, Solari MG, Nazzal JA, Nielsen GP, Arn JS, et al. Split tolerance to a composite tissue allograft in a swine model. Transplantation. 2003;75(1):25-31) [32].

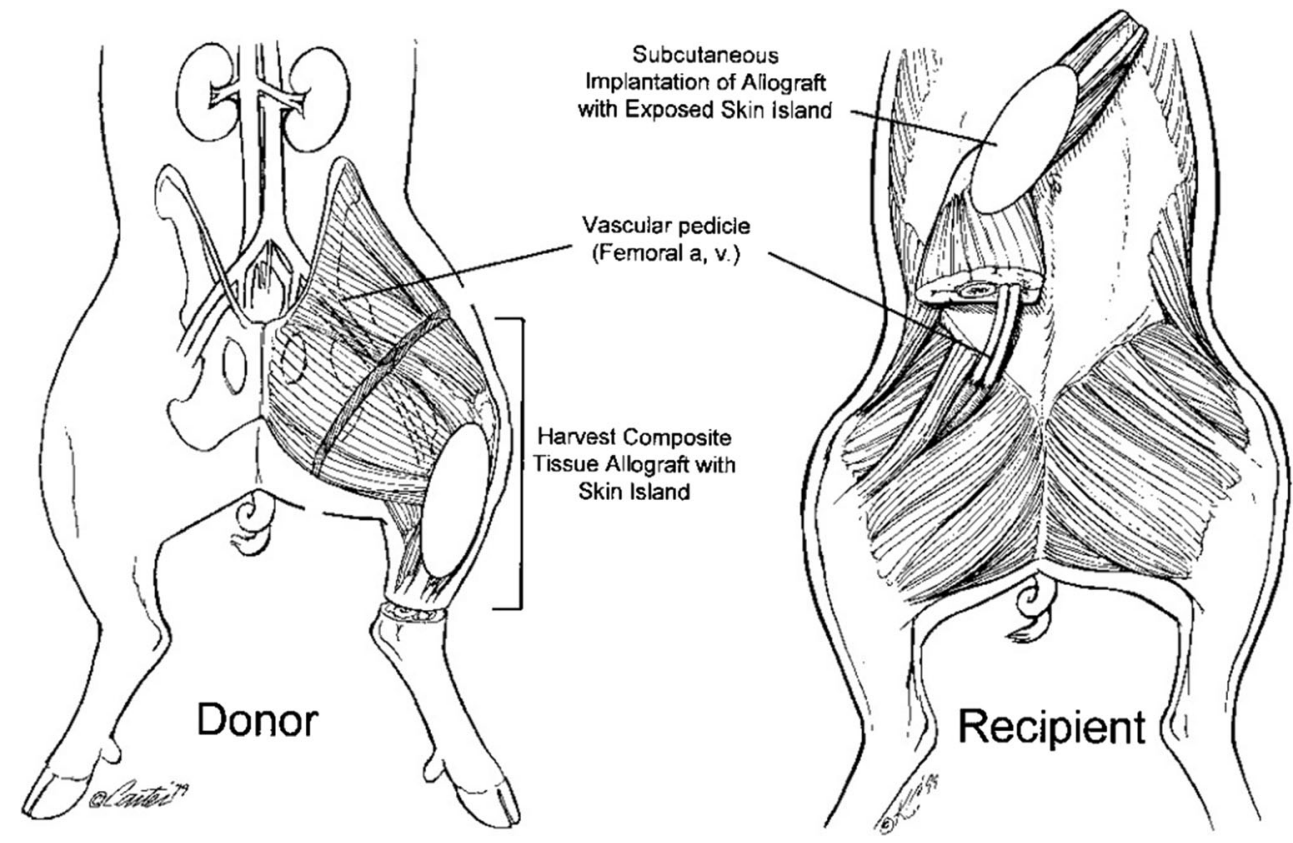

of the accepted allografts, is a local tolerogenic response not seen systemically $[38 \bullet \bullet$. In this model, chimerism was associated with graft tolerance and not necessarily through regulatory $\mathrm{T}$ cell mechanisms.

These protocols have been demonstrated to be technically feasible, reproducible, and well tolerated by swine. Protocols that have induced long-term acceptance of VCA containing skin across multiple MHC barriers in swine still have not defined the minimum requirements to induce those mechanisms. Continuing studies investigate the mechanisms of tolerance, the minimum conditioning regimens, and complications including GVHD.

\section{CANINES}

Canine models have historically been used to study the surgical and immunological aspects of organ and hematopoietic stem cell transplantation. These models differ as canines tend to be outbred, which provides much more genetic diversity of their MHC antigens when compared with NHP or swine, which are typically inbred. Canines are also more immunologically mature than other animals at the time of experimentation. These facts make canines a unique and relevant large animal model [26].

The first successful use of an immunosuppressive agent was in the canine model [37], and canines were used as an initial model of limb allotransplantation. First models of limb allotransplantation with 6-mercaptopurine or azathioprine with antilymphocyte serum and hydrocortisone were complicated by systemic toxicity resulting in uncontrollable wound sepsis and pneumonia [39, 40]. A pre-clinical trial by
Shengwu et al [41] investigated a cadaveric technical model and a facial/scalp VCA. Technical studies concluded that canines have similar facial vasculature and nerve anatomy compared to humans [42]. After anatomic studies, five beagle dogs with negative MHC cross-match were treated with antibiotics, CsA, and steroids. Rejection was treated with increased CsA and prednisone. While one infectious complication (pneumonia) was observed, remaining dogs had VCA survival from 201 to 402 days [41].

Mathes et al investigated a model of VCA that used a rectus muscle flap based on the deep inferior epigastric arteries and veins (DIEA/V) and later modified to include the external iliac artery and vein as donor vessels [43]. Studies using genetically matched donor-recipient pairs for dog leukocyte antigen (DLA) based on MHC-I and MCH-II microsatellite markers then followed. VCA rectus transplants were performed without immunosuppression, and all underwent rejection around POD 12 with subsequent vascular thrombosis, and complete rejection occurred between POD 15 and POD 30 [43]. Investigations of mixed hematopoietic chimeras in canines used sub-lethal doses of $1-2$ Gy of total body irradiation (TBI) before a brief course of immunosuppression after DLAidentical bone marrow transplantation. VCAs from the marrow donors were performed after a median of 36 months (range, 4-54 months) after hematopoietic cell transplantation (HCT). Mixed chimeras that received VCAs were matched for DLAs, but were minor-antigen mismatched. After bone marrow transplantation, animals were treated with MMF and either CsA or rapamycin. Allografts in recipient chimeras demonstrated long-term survival with successful graft follow-up lasting from 52 to greater than 90 weeks postoperatively. Graft histology demonstrated elevated levels of 
$\mathrm{CD} 3+/ \mathrm{FOXP} 3+\mathrm{T}$ regulatory cells as compared to rejecting controls [44•]. The canines that did not receive hematopoietic stem cell transplantation (HSCT) rejected within 3 weeks, implicating HSCT for induction of tolerance. This model differed from studies that revealed split-tolerance where skin was rejected, but the underlying muscle and fascia are preserved. The success of this canine VCA model, including tolerance to the skin, was believed to be dependent on tolerance to non-MHC antigens shared by HSC cells and all of the donor tissues [44•].

\section{CONCLUSION}

The use of large animal models for pre-clinical VCA established the foundation of immunological and technical understanding, and importantly, a critical, chronological precursor to actual human application. Familiarity with the technical aspects of VCA transplantation supported clinical explorations of human hand and face transplantation. Each large animal model first defined surgical and technical approaches, and later investigated immunobiology, neuroregenerative, and complications that are crucial in improving the outcomes of vascularized composite allotransplantation. Nonhuman primate, swine, and canine models provided insight into chronic immunosuppressive regimens and tolerogenic approaches. Achieving immunologic tolerance through chimerism has been demonstrated in swine and canine models, while as yet, no nonhuman primate model has been developed to achieve tolerance. Similar to all other transplants, VCA large animal studies will support advances in immunosuppressive approaches and move towards an applicable strategy to achieve immunologic tolerance.

\section{Compliance with Ethics Guidelines}

Conflict of Interest Jhade D. Woodall, Benjamin D. Schultz, Michael Sosin, and Rolf N. Barth declare that they have no conflict of interest.

Human and Animal Rights and Informed Consent This article does not contain any studies with human or animal subjects performed by any of the authors.

\section{References}

Papers of particular interest, published recently, have been highlighted as

- Of importance

•- Of major importance

1. Levi DM, Tzakis AG, Kato T, Madariaga J, Mittal NK, Nery J, et al. Transplantation of the abdominal wall. Lancet. 2003;361(9376): 2173-6.
2. Strome M, Stein J, Esclamado R, Hicks D, Lorenz RR, Braun W, et al. Brief report: Laryngeal transplantation and 40-month followup. N Engl J Med. 2001;344(22):1676-9.

3. Fattah A, Cypel T, Donner EJ, Wang F, Alman BA, Zuker RM. The rirst successful lower extremity transplantation: 6-year follow-up and implications for cortical plasticity. Am J Transplant. 2011;11(12):2762-7.

4. Egerszegi EP, Samulack DD, Daniel RK. Experimental models in primates for reconstructive surgery utilizing tissue transplants. Ann Plast Surg. 1984;13(5):423-30.

5. Daniel RK, Egerszegi EP, Samulack DD, Skanes SE, Dykes RW, Rennie WR. Tissue transplants in primates for upper extremity reconstruction: a preliminary report. J Hand Surg [Am]. 1986;11(1):1-8.

6. Stark GB, Swartz WM, Narayanan K, Møller AR. Hand transplantation in baboons. Transplant Proc. 1987;19(5):3968-71.

7. Stevens HP, Hovius SE, Vuzevski VD, van Nierop PW, Gotte M, Roche NA, et al. Immunological aspects of allogeneic partial hand transplantation in the rhesus monkey. Transplant Proc. 1990;22(4): 2006-8.

8. Hovius SE, Stevens HP, van Nierop PW, Rating W, van Strik R, et al. Allogeneic transplantation of the radial side of the hand in the rhesus monkey: I. Technical aspects. Plast Reconstr Surg. 1992;89(4):700-9.

9. Stevens HP, Hovius SE, Heeney JL, van Nierop PW, Jonker M. Immunologic aspects and complications of composite tissue allografting for upper extremity reconstruction: a study in the rhesus monkey. Transplant Proc. 1991;23(1 Pt 1):623-5.

10. Cendales LC, Xu H, Bacher J, Eckhaus MA, Kleiner DE, Kirk AD. Composite tissue allotransplantation: development of a preclinical model in nonhuman primates. Transplantation. 2005;80(10):1447-54.

11. Silverman RP, Banks ND, Detolla LJ, Shipley ST, Panda A, Sanchez RA, et al. A heterotopic primate model for facial composite tissue transplantation. Ann Plast Surg. 2008;60(2):209-16.

12. Barth RN, Bluebond-Langner R, Nam A, Stanwix M, Shipley S, Bartlett ST, et al. Facial subunit composite tissue allografts in nonhuman primates: I. Technical and immunosuppressive requirements for prolonged graft survival. Plast Reconstr Surg. 2009;123(2):493-501.

13. Barth RN, Nam A, Stanwix MG, Kukuruga D, Drachenberg CB, Bluebond-Langner R, et al. Prolonged survival of composite facial allografts in non-human primates associated with posttransplant lymphoproliferative disorder. Transplantation. 2009;88(11):124250 .

14. Barth RN, Rodriguez ED, Mundinger GS, Nam AJ, Ha JS, HuiChou $\mathrm{H}$, et al. Vascularized bone marrow-based immunosuppression inhibits rejection of vascularized composite allografts in nonhuman primates. Am J Transplant. 2011;11(7):1407-16. Heterotopic facial transplantation model shows survival benefit when bone is included with transplanted flap.

15. Mundinger GS, Munivenkatappa R, Drachenberg CB, Ha JS, Vaca EE, Shipley ST, et al. Histopathology of chronic rejection in a nonhuman primate model of vascularized composite allotransplantation. Transplantation. 2013;95(10):1204-10.

16. Mundinger GS, Nam AJ, Hui-Chou HG, Stanwix MG, Jones LS, Drachenberg CB, et al. Nonhuman primate model of fibula vascularized composite tissue allotransplantation demonstrates donorrecipient bony union. Plast Reconstr Surg. 2011;128(6):1193-204.

17. Brazio PS, Munivenkatappa RB, Bojovic B, Ha JS, Brown EN, Hess AS, et al. Regulatory T cells are not predictive of outcomes in a nonhuman primate model of vascularized composite allotransplantation. Transplantation. 2013;96(3):267-73.

18. Kaufman CL, Breidenbach W. World experience after more than a decade of clinical hand transplantation: update from the Louisville hand transplant program. Hand Clin. 2011;27(4):417-21.

19. Ren X, Shirbacheh MV, Ustüner ET, Zdichavsky M, Edelstein J, Maldonado C, et al. Osteomyocutaneous flap as a preclinical composite tissue allograft: swine model. Microsurgery. 2000;20(3):143-9. 
20. Ustüner ET, Majzoub RK, Ren X, Edelstein J, Maldonado C, PerezAbadia G, et al. Swine composite tissue allotransplant model for preclinical hand transplant studies. Microsurgery. 2000;20(8):400-6.

21. Jin J, Williams CP, Soltanian H, Smith MK, Pearl J, Sanabria J, et al. Use of abdominal wall allotransplantation as an alternative for the management of end stage abdominal wall failure in a porcine model. J Surg Res. 2010;162(2):314-20.

22. Yamada K, Vagefi PA, Utsugi R, Kitamura H, Barth RN, LaMattina $\mathrm{JC}$, et al. Thymic transplantation in miniature swine: III. Induction of tolerance by transplantation of composite thymokidneys across fully major histocompatibility complex-mismatched barriers. Transplantation. 2003;76(3):530-6.

23. Leto Barone AA, Leonard DA, Torabi R, Mallard C, Glor T, Scalea $\mathrm{JR}$, et al. The gracilis myocutaneous free flap in swine: an advantageous preclinical model for vascularized composite allograft transplantation research. Microsurgery. 2013;33(1):51-5.

24. Ustüner ET, Zdichavsky M, Ren X, Edelstein J, Maldonado C, Ray $\mathrm{M}$, et al. Long-term composite tissue allograft survival in a porcine model with cyclosporinee/mycophenolate mofetil therapy. Transplantation. 1998;66(12):1581-7.

25. Jones Jr JW, Ustüner ET, Zdichavsky M, Edelstein J, Ren X, Maldonado C, et al. Long-term survival of an extremity composite tissue allograft with FK506-mycophenolate mofetil therapy. Surgery. 1999;126(2):384-8.

26. Kirk AD. Crossing the bridge: large animal models in translational transplantation research. Immunol Rev. 2003;196:176-196.

27. Lee WP, Rubin JP, Cober S, Ierino F, Randolph MA, Sachs DH. Use of swine model in transplantation of vascularized skeletal tissue allografts. Transplant Proc. 1998;30(6):2743-5.

28. Gianello PR, Sachs DH. Effect of major histocompatibility complex matching on the development of tolerance to primarily vascularized renal allografts: a study in miniature swine. Hum Immunol. 1996;50(1):1-10.

29. Lee WP, Rubin JP, Bourget JL, Cober SR, Randolph MA, Nielsen GP, et al. Tolerance to limb tissue allografts between swine matched for major histocompatibility complex antigens. Plast Reconstr Surg. 2001;107:1482-90.

30. Bourget JL, Mathes DW, Nielsen GP, Randolph MA, Tanabe YN, Ferrara VR, et al. Tolerance to musculoskeletal allografts with transient lymphocyte chimerism in miniature swine. Transplantation. 2001;71(7):851-6.

31. Mathes DW, Randolph MA, Bourget JL, Nielsen GP, Ferrara VR, Arn JS, et al. Recipient bone marrow engraftment in donor tissue after long-term tolerance to a composite tissue allograft. Transplantation. 2002;73(12):1880-5.

32. Mathes DW, Randolph MA, Solari MG, Nazzal JA, Nielsen GP, Arn JS, et al. Split tolerance to a composite tissue allograft in a swine model. Transplantation. 2003;75(1):25-31.

33. Cetrulo Jr CL, Torabi R, Scalea JR, Shimizu A, Leto Barone AA, Gillon BC, et al. Vascularized composite allograft transplant survival in miniature swine: is MHC tolerance sufficient for acceptance of epidermis? Transplantation. 2013;96(11):966-74. Using $a$ model of established MHC tolerance the authors show that MHC tolerance alone is not sufficient for tolerance of skin.

34. Fuchimoto Y, Huang CA, Yamada K, Shimizu A, Kitamura H, Colvin RB, et al. Mixed chimerism and tolerance without whole body irradiation in a large animal model. J Clin Invest. 2000;105(12):1779-89.

35. Kuo YR, Chen CC, Shih HS, Goto S, Huang CW, Wang CT, et al. Mesenchymal stem cells prolong composite tissue allotransplant survival in a swine model. Transplantation. 2009;87(12):1769-77.

36. Kuo YR, Chen CC, Shih HS, Goto S, Huang CW, Wang CT, et al. Prolongation of composite tissue allotransplant survival by treatment with bone marrow mesenchymal stem cells is correlated with T-cell regulation in a swine hind-limb model. Plast Reconstr Surg. 2011;127(2):569-79.

37. Kuo YR, Chen CC, Goto S, Huang YT, Wang CT, Tsai CC, et al. Immunomodulatory effects of bone marrow-derived mesenchymal stem cells in a swine hemi-facial allotransplantation model. PLoS One. 2012;7(4):e35459.

38.• Leonard DA, Kurtz JM, Mallard C, Albritton A, Duran-Struuck R, Farkash EA, et al. Vascularized Composite Allograft Tolerance Across MHC Barriers in a Large Animal Model. Am J Transplant. 2014;14:343-55. Using a non-myeloblative conditioning with BMT the authors transplant a myocutaneous flap in a haplotype mismatch animal with tolerance to all components of the graft. This is associated with chimerism and GVHD.

39. Goldwyn RM, Beach PM, Feldman D, Wilson RE. Canine limb homotransplantations. Plast Reconstr Surg. 1966;37:184-95.

40. Lance EM, Inglis AE, Figarola F. Transplantation of the canine hind limb. Surgical technique and methods of immunosuppression for allotransplantation. A preliminary report. J Bone Joint Surg Am. 1971;53:1137-49.

41. Shengwu Z, Qingfeng L, Hao J, Banich J, Kaiding F, Benson C, et al. Developing a canine model of composite facial/scalp allograft transplantation. Ann Plast Surg. 2007;59(2):185-94.

42. Eduardo Bermú Dez L, Santamaría A, Romero T, Calderó DF. Experimental model of facial transplant. Plast Reconstr Surg. 2002;110:1374-5.

43. Mathes DW, Noland M, Graves S, Schlenker R, Miwongtum T, Storb R. A preclinical canine model for composite tissue transplantation. J Reconstr Microsurg. 2010;26(3):201-7.

44. Mathes DW, Huang B, Graves SS, Edwards J, Chang J, Storer BE, et al. Tolerance to vascularized composite allografts in canine mixed hematopoietic chimeras. Transplantation. 2011;92:1301-8. This study demonstrates that a nonmyeloablative hematopoeitic stem cell transplant conditioning regimen is an effective means of establishing stable, mixed chimerism with subsequent evidence of donorspecific tolerance. Further, T-regulatory cells may participate in maintenance of the vascularized composite allograft. 